This series of experiments proved that which was only indicated in the ascents with a free balloon, viz., that the change of temperature with increase of elevation has a diurnal range, the change being the greatest at about midalay and the early afternoon hours, decreasing till about sunset, at which time, when the sky was free from clouds, there was little or no change of temperature up to the height of several hundred feet. I was not able, by means of M. Giffard's balloon, to take any observations at about noon and early afternoon hours, nor any observations after sunset, as the balloon never ascended at these times; but such observations were greatly needed, as there seemed to be at this time a very high probability that the temperature of the air at night must increase with elevation.

A thermometer was placed at the height of 22 feet, sufficiently protected from the effects of radiation, and a second one at the height of 4 feet, and eleven years' observations of these instruments have been taken daily at 9 A.M. ; noon; 3 P.M.; and 9 P.M.

These observations were reduced by taking the difference between the readings of the two thermometers and affixing the sign + to that difference when the temperature was higher at the higher elevation; and the sign - when lower. By taking the mean differences for each month between the temperatures at 22 feet and 4 feet, it was found that at all hours of the day during the months of January, February, November, and December, in the afternoon hours of March, September, and October, and night hours throughout the year, the sign was + and that it was - at all other times, clearly indicating the fact of an increase of temperature with increase of elevation during the night hours throughout the year.

\section{THF HEAT PHENOMENA ACCOMPANYING MUSCULAR ACTION}

IIE fact that in the living muscle heat always appears when the muscle does work (Heidenhain having shown that of two muscles equally weighted and undergoing equal contractions, one doing external work, while the other does none, the former gives out more heat than the latter), is an exception to the general rule in mechanics, that heat disappears when work is done. It is not, however, in contradiction to the general principle of the conservation of energy, but shows that in the living muscle, when stimulated to action, molecular processes occur, which, along with the doing of work, cause a development of heat. The relation of the heat developed to the work done had not been determined with any satisfactory accuracy, probably owing to the want of sufficiently delicate apparatus, though it might naturally be expected to help to an understanding of the phenomena. The subject has been taken up by $M$. Nawalichin, who, favoured by the experimental means at hand in M. Heidenhain's Physiological Institute, made a careful examination of the development of heat in the active muscle. The experiments were very clifficult and tedious, and by reason of the smallness of the values to be measured, required very great foresight and care in the experimental arrangements. The full account of this investigation is given in Pflizger's Archiv.

The first series of experiments bore on the question of the production of heat when a particular muscle of the frog is excited, through the nerve, by stimuli of increasing strength to increasing contractions. As, during the experiments, the excitability of the preparation varies, the relation to the strength of stimulus was left out of account, and only the ratio between development of heat and height of contraction examined. The height of contraction was indicated graphically by the muscle itself on a smoke-blackened plate. The development of heat was measured by the deflection of a fine thermo-multiplier, and the stimulation of the nerve was effected by accurately measurable electric actions. The observations were only made when the needle was entirely at rest, which was very difficult to secure, so sensitive was the apparatus.

The tabulated numbers from experiment show: (i) that the sum of the vis viva, liberated in the muscle by increasing stimuli, increases only so long as the lifting-heights (Hubhöhen) increase. With a certain amount of stimulus when produced by the sending of a constant current, the height of contraction reaches a maximum, and therewith, too, the production of heat. With a particular method of stimulation there is, under certain conditions, a fresh increase of the amount of contraction above the maximum amount, the so-called "supermaximal" contrac- tion; where this occurred, the heat-production also rose. I may therefore be said that in general the development of heat increases with increased lifting-height, and decreases with decreased lifting-height.

The increase in heat-production, however, does not take place proportionally to the increase in lifting.height, but in much quicker ratio. Of this unexpected result M. Nawalichin assured himself by repeated discussion of the numerical values obtained; but he did not succeed in determining more precisely the law of increase.

This result led to the expectation that the same mechanical work of a muscle would be accompanied by unequal heating when the muscle raised a weight to the same height by several small contractions, and when it raised it by one great contraction. In a great contraction more heat would become free than in several small ones, the sum of which was equal to the great. Experiments (though some were difficult) fully confirmed this, especially after it was ascertained that the cooling during the longer period of the several smaller contractions as against the shorter duration of the great contraction, did not play a part.

It is shown, then, that as the stimulation increases, the temperature of the muscle, and accordingly the exchange of material, increase in much quicker ratio than the nechanical work, and that the stronger the stimulation the less favourable is the relation of the exchange of material to the doing of work.

These facts are in accordance, as M. Nawalichin points out, with the common experience that the climbing of a hill is much less heating and exhausing when we go zigzag than when we go straight up. In the former case a greater number of small lifcings of the body result in the same doing of work as occurs in the second case through a smaller number of great liftings. The exchange of material, as the second series of experiments show, must essentially be greater in the second case than in the first; and on the amount of it depends, on the one hand, the development of heat, on the other the exhaustion.

In order to get at the inner connection of the phenomena observed, M. Nawalichin sought first to decide the question whether the accelerated increase in production of heat was die to the increase of the stimulus in itself or to the increase of the contraction produced by the increased stimulation. According to Helmholtz's observations, when a muscle is subjected to rwo maximum stimuli, one following close on the other, the secoud stimulus produces an increase of contraction only when, at commencement of the second contraction, the first has already reached a considerable height. If this be not the case, as happens if the interval of the two simuli be less than $\frac{1}{6} \overline{0}$ th of a second, the two stimulations produce no greater contraction than each alone. Now in what way does the production of heat occur in this latter case? Experiment showed that also with double stimulation of the nerve, an increase of the heat-development only occurred when it had as result an increase in the height of contraction; the increase of the stimulus in itself is thus without influence on the amount of heat-production. Hence the cause of the quicker increase of the heat-production. That of the amount of contraction must be sought in conditions operative during the course of the contraction.

To cletermine these conditions the author made experimental inquiry into the relation of heat-development to the states of tension of the muscle during the progress of contraction. He found that the muscle developed less heat the less its tension before action; with which may be mentioned that this tension of the muscle, weighted and stretched by the weight, is smaller the more it has, through contraction, approximated to the natural length. Experiments, also, as to the relation of the heat-production to the change of state of tension during the act of contraction showed an influence of this, such that in each moment of action the quantity of heat depends on the tension. This suggested the idea that the greater heat-production with increasing stimulation is perhaps a consequence of the longer duration of the stronger contraction. The experiments proved, however, that this idea is not justified, for the muscle made small and great contractions in the same time.

As to the nature of the internal processes in the muscle, which may be the basis of the phenomena observed, M. Nawalichin offers the following remarks:- -

"We know that the contracting muscle is a body of variable elasticity ; with increased contraction its elastic force becomes less, its extensibility greater. When the muscle raises a given weight about four millimetres, the external work for each millimetre of the lifting-height is indeed the same but nevertheless the 
doing of the same external work for every successive unit-length of the lifting-height will require a larger sum of contractile forces than for every earlier one, since the muscle, even with progressive contraction, varies as to its elastic properties in the direction of an increase of its extenstbility. Upon the weight hung to the muscle act, when contraction occurs, both the contractile and the elastic forces of the muscle. ... In the $\operatorname{sum}(c+e)$ of the contractile $(c)$ and the elastic forces $(c), e$ becomes at first (during the contraction) smaller, with the natural unweighted length of the muscle equal to $\mathrm{kil}$, and later, even negative. If the weight, then, be lifted a number of units of length, the value of $c$ must increase with increasing contraction. . . . But an increase of the contractile force is only possible through increased transformation of elasticity into vis vivu, that is, through exchange of material, which finds its expression in the increased formation of heat which I have observed. Thus, if I mistake not, the facts discovered by me connect themselves with other relations already known, and will find their application in a future theory of muscular forces."

\section{UNIVERSITY AND EDUCATIONAL INTELLIGENCE}

OxForD. - It is stated that the Home Secretary has appointed ins joint secretaries to the Oxford University Commission the kev. Thomas Vere Bayne, Censor and Student of Christ Church, and Thomas Francis Dallin, late Fellow of Queen's College, and Iublic Orator of the University of Oxford.

CAMbridge. - The death is announced of Dr. Geldart, Master of Trinity Hall, Cambridge, in the eighty-first year of his age. He had held the mastership twenty-five years, having succeeded Sir I Ierbert Jenner Fust. Dr. Geldart graduated as severteenth wrangler in 1818 .

ION non.--Besides those already announced, the Rev. J. T. Blake and Mr. Lebour are, we believe, candidates for the vacant geological chair in University College.

NoTTINGHAM, - The ceremony of laying the foundation-stone of the University buildings at Nottingham has been fixed for Thursday, the 27 th inst. The ceremony will be performed at noon by the Mayor, and subsequently there will be a public luncheon in the Albert Hall, at which Mr. Gladstone is expected to be present. The cost of the buildings, including the land, will be $60,000 \%$ Of this sum an anonymous donor has contributed Io, $000 l$, and the remainder will be found by the Corporation, who have given the site. There will be lecture and class-rooms for the promotion of the Cambridge University Extension Scheme, which, it will be remembered, was first incorporated at Nottingham, and which has since been carried out successfully in several centres of industry. There will also be class-rooms, laboratory, \&c., for the use of the students in the science classes in connection with the local Mechanics' Institution, as well as rooms for the Free Library and the Natural History Museum.

\section{SOCIETIES AND ACADEMIES}

PARIS

Academy of 3ciences, September 10.-M. Peligot in the chair.--Experimental researches on the mechanism of the formation of sugar in the liver, by M. Cl. Bernard.--Referring to the preceding paper, M. A. Trécul then read a treatise on the formation of starch and of cellulose in plants.-M. Th. du Moncel then presented to the Academy a copy of his "Recherches sur les meilleures conditions des électro-aimants."-On the variation of atmospheric pressure at different altitudes, determined at the Puy-de-Dôme Observatory, during the cyclones of last winter, by M. Alluard. The author found, on comparing the barometrical readings at the Puy-de.Dôme Observatory with those of Clermont Observatory, that the most remarkable discrepancies existed, the barometer having frequently risen several millimetres at Clermont, when at the same time it fell considerably on the Puy-de-Dôme. He asks whether the supposition is justified that, while a cyclone passes over the land, other smaller cyclones are situated inside of it and remain at different heights, without reaching the ground? Or does the strange phenomenon result from local reasons which appertain to the relief of the Dome's chain and to the relative position of the two observa- tories? In all cases this phenomenon shows the necessity of studying the atmosphere in different layers and the great import. ance of the Puy-de-Dôme Observatory.-On a process of preserving the flesh of fish (extract from a note), by M. R. M. d'Amélio.- On the presence of phylloxera in the department of Loir-et-Cher, by M. J. Duplessis. The writer has found that the pernicious insect has now penetrated as far as Villebarron, and the district infested near Orleans now has the shape of a vast equilateral triangle of 60 kilometres side. $-\mathrm{M}$. Ed. Prillieux then read a note on the causes which have brought about the invasion of phylloxera into the Vendôme district.--M. J. Maistre in a letter to M. Dumas speaks of the effects of sulphocarbonates against the insects.-The Minister for Agriculture and Commerce wrote a letter to M. Dumas on the same subject.-M. Faye then drew the attention of the Academy to some interesting results obtained at Washington Observatory by the observation of the two satellites of Mars recently discovered. It appears from a communication made by Admiral \}. Rodgers, that in the telegram first sent to Europe by the Smithsonian Institution at Washington there was a mistake, viz., in ascribing to the inner satellite a distance of fifty seconds; half of the major axis of its orbit amounts only to thirty-three seconds of arc. -A letter was then read by the president from M. Ch. Lamey on some observations he made during the winter of $1864-65$, and which caused him to believe that Mars is surrounded by a ring of asteroids of all sizes, and as a whole resembling, in some respects, the ring of Saturn M. Lamey had observed an uncertain reddish light on each side of the disk of the planet and corresponding nearly to its equator. He directs the attention of the observers of the two new satellit $\subseteq$ s to this peenomenon.-M. Leverrier then announced the discovery of another new planet in the zone between Jupiter and Mars, by Mr. Watson, at Ann Arbor, on the 3rd instant, R.A. $23^{\prime}$ Iom. Dec. $+0^{\circ} 45^{\prime}$. Daily motion in R.A. 55 s. ; in Decl. - I' ; magnitude II. - On the theory of the small motions of a weighty point on a fixed suface which is described round a vertical axis of revolution, by $\mathrm{J}$. Boussinesq. - On locomotives of the compound system, by $M$. $\Lambda$. Mallet. - On the specific heat and the melting heat of platinum, by $M$. J. Violle. In the course of experiments made by this gentleman he found the true melting-point of pure silver at $954^{\circ} \mathrm{C}$.-A note by M. V. Neyreneuf on the specific induction power.-On nitroso-guanidine, by M. Jousselin.-On the methods which the ancients must have employed to lift and transport the great Celtic or Gallic mono. liths, by M. E. Robert. - A note by M. L. Hugo on some curves representing certain elements of the planetary system.

\section{CONTENTS}

PAGH

The Work of the Iron and Steel Institute. . . . . 433 Coin's Brology of Plants. By Prof. W. R. MicNab.$:$ : 435 U R BOOK SHRLF :-

Mackay's "Physiography and Physical Geography" . . . . . 437

"Fisher's "Book of Algebra" . . . . . . . . . . . . 437

Bulletin of the United States Geological and Geographical Survey of the Territories."-A. G. ButLer.

LetTERS TO THE EMITOR:-

Temperature of Moon's Surface.-The EARL of RosSE, T.R S. - $43^{8}$

Rainfall and Sun-Spots in India.-E. D. ARCHBBALD $: 2: 43^{8}$

The Australian Monotrenes. - P. L. S. ; W. A. FORBES : : : : 439

English Names of Wild Flowers and Plants. -J. WILLIS . . . . 439

Sorne of the 'Troubles of John O'Toole respecting Potential On the Supposed Action of Light on Combustion.-G. SAVARY :

OUR Astronomical COLUMN :-

The Satellites of Mars . : .

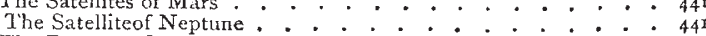

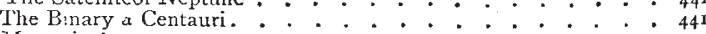

Meteoric Astronomy . . . . . . . . . . . . . . . 441

Chemical Notes

Action of Organic Substances increasing the Sensitiveness of certain Silver Salts

Heat of Combustion of Oxygen and Hydrogen in Closed Vessels :

On Vapour Volumes in Relation to Avogadro's Law . - $\dot{C}^{-} \cdot$

Chemical Constitution of the Minerals Hatchetolite and Samar

skite, from North Carolina

On a New Class of Bodies termed Platoiodnitrites : : : 44

A New $A$ sid.

Remarkable Plants, iv-The blue Gun tree (Euccilyptus globulus, Labil.) (With Illastration). - . C (Eid ilfantegazza on the Relative Lengths of the Index and "Ring" Fingers. By J. C. Galton. . . . . . . . . . 444 Notes . : : : : 44 INTRODUCTION AND SUCCESSION OF VERTEBRATE LIFE IN AMERICA ON NOCTURNAL INCREASE OF TEMPHRATURE Wirh EleVATION. By The Heat Phenomena accompanying Musculak Action * * 45

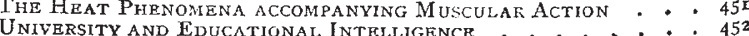

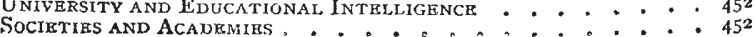

